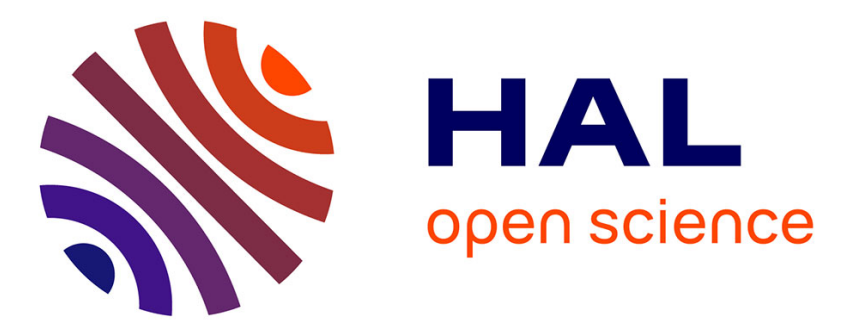

\title{
Linkages between snow cover, temperature and rainfall and the North Atlantic Oscillation over Morocco
}

\author{
A. Marchane, Lionel Jarlan, A. Boudhar, Y. Tramblay, L. Hanich
}

\section{To cite this version:}

A. Marchane, Lionel Jarlan, A. Boudhar, Y. Tramblay, L. Hanich. Linkages between snow cover, temperature and rainfall and the North Atlantic Oscillation over Morocco. Climate Research, 2016, 69 (3), pp.229 - 238. 10.3354/cr01409 . hal-01871875

\section{HAL Id: hal-01871875 \\ https://hal.umontpellier.fr/hal-01871875}

Submitted on 26 Nov 2021

HAL is a multi-disciplinary open access archive for the deposit and dissemination of scientific research documents, whether they are published or not. The documents may come from teaching and research institutions in France or abroad, or from public or private research centers.
L'archive ouverte pluridisciplinaire HAL, est destinée au dépôt et à la diffusion de documents scientifiques de niveau recherche, publiés ou non, émanant des établissements d'enseignement et de recherche français ou étrangers, des laboratoires publics ou privés. 


\title{
Linkages between snow cover, temperature and rainfall and the North Atlantic Oscillation over Morocco
}

\author{
A. Marchane ${ }^{1, *}$, L. Jarlan ${ }^{2}$, A. Boudhar ${ }^{3}$, Y. Tramblay ${ }^{4}$, L. Hanich ${ }^{1}$ \\ ${ }^{1}$ Laboratoire de Géoressources - Unité associée au CNRST (URAC42), Département des Sciences de la Terre, \\ Faculté des Sciences et Techniques, Université Cadi Ayyad, Av. A. Khattabi, BP 549, 40000 Marrakech, Morocco \\ ${ }^{2}$ IRD, Centre d'Etudes Spatiales de la BIOsphère, Bpi 2801, 18 avenue Edouard Belin, 31401 Toulouse Cedex 9, France \\ ${ }^{3}$ Université Sultan Moulay Slimane, Faculté des Sciences et Techniques, B.P. 523, Béni-Mellal, Morocco \\ ${ }^{4}$ IRD, Hydrosciences Montpellier, 34090 Montpellier, France
}

\begin{abstract}
Snowpack significantly contributes to water resources in North Africa. The objective of this work was to analyze the impact of the North Atlantic Oscillation (NAO) on rainfall and temperature in Morocco at a sub-seasonal scale and to evaluate, for the first time, linkages between the NAO and snow cover area (SCA) derived from remote sensing observations. For this purpose, we analyzed daily SCA products (2000-2013) from the MODIS sensor, meteorological data from 37 stations (1993-2011), NCEP re-analysis of surface air temperature and rainfall rate, and a monthly NAO index. The linear linkages sought using simple correlation analysis demonstrated that negative (positive) NAO (1) is associated with enhanced (reduced) rainfall in December and February for the northern part of the country; (2) occurs with above-normal (below-normal) temperature and, in contrast with rainfall, the correlation persists far inland and late in the season. These results highlight a possible competing influence of NAO on the snowpack dynamic through rainfall and temperature. Indeed, negative (positive) NAO tends to favor earlier (later) melting and lesser (greater) SCA in spring (April-May) through milder temperatures. Results have direct implications for seasonal forecast of SCA in Morocco.
\end{abstract}

KEY WORDS: $\quad$ Snow cover $\cdot$ MODIS $\cdot$ NAO $\cdot$ Semi-arid $\cdot$ Mediterranean areas Resale or republication not permitted without written consent of the publisher

\section{INTRODUCTION}

Water held in snow pack is of considerable societal importance for many watersheds in semi-arid areas of the South Mediterranean, in particular for irrigated areas that are located downstream of many catchments with a rainfall-snowmelt functioning (Viviroli et al. 2007). Indeed, Boudhar et al. (2009) demonstrated that between 15 and $50 \%$ of wadi discharge can be attributed to snow melt in the Tensift catchment of the Marrakech region in Morocco.
Optical remote sensing offers an alternative to in situ data for extracting snow cover information in mountainous areas where ground measurement networks are scarce, especially in the South Mediterranean countries. To this objective, the contrasted spectral behavior of snow between the visible and the medium part of the spectrum (Painter \& Dozier 2004) was exploited in the past to build the Normalized Difference Snow Index (NDSI; Crane \& Anderson 1984, Hall et al. 2001). Various operational snow products based on NDSI exist (Frei et al. 2012), but the only one with spatial resolution $(500 \mathrm{~m})$ and short revisit 
time (1-2 d) compatible with the monitoring of the highly dynamic behavior of snow pack in the South Mediterranean mountainous areas is derived from the Moderate Resolution Imaging Spectroradiometer (MODIS) observations. The accuracy of these products has been demonstrated in various parts of the world in recent studies, including Morocco (Marchane et al. 2015).

The North Atlantic Oscillation (NAO; Marshall et al. 2001) is the prominent mode of the atmospheric variability of the northern hemisphere (Barnston \& Livezey 1987) and its impact on North African rainfall during winter is well known (Lamb \& Peppler 1987, Hamly et al. 1998, Knippertz et al. 2003, Mariotti \& Dell'Aquila 2012). Although less documented, the NAO influence on air temperature at the surface has also been studied. It has been shown that the regions affected by westerlies (Southern Europe and northern Africa during the negative phase) exhibit higher than normal temperature (Hurrell \& Van Loon 1997, Wang et al. 2005). In particular, Hurrell (1996) found that $31 \%$ of the variance for winter surface temperature (December to March, DJFM) in the northern hemisphere above $20^{\circ} \mathrm{N}$ could be related to NAO and this could even impact vegetation phenology in Europe as shown by Cook et al. (2005). López-Moreno et al. (2011) analyzed DJFM temperature and rainfall in the Mediterranean mountains and suggested that the NAO is likely to strongly govern snowpack dynamics in the region. In particular, the question arises how this potential double effect of NAO on both rainfall and temperature affects the dynamics of snowpack. More recently, Kim et al. (2013) studied the European winter snow cover variability and its linkage with the NAO, highlighting the need to study this at a sub-seasonal scale; this is particularly so for the semi-arid South Mediterranean Mountains with regard to the highly dynamical behavior of the snowpack (Schultz \& De Jong, 2004, Boudhar et al. 2010). In view of the implications for water resources, there is a pressing need for a better understanding of the factors governing snow cover variability in the South Mediterranean at the sub-seasonal scale.

The objective of this work was twofold: (1) to analyze the impact of the NAO on rainfall and temperature in Morocco at a sub-seasonal scale and (2) to evaluate, for the first time, linkages between the NAO and snow cover area (SCA) derived from remote sensing observations.

\section{DATA AND METHODS}

\subsection{Study region}

The study area covers the Moroccan Atlas Mountains. It is composed of the 7 main catchments of Morocco, with a mixed influence of rainfall and snowmelt. Fig. 1 displays the catchment boundaries together with the topography of the area derived from ASTER-DEM (Abrams et al. 2010). The Atlas region encompasses areas of considerable importance for Morocco's agriculture, with numerous irrigated areas in the downstream sections of the catchments, including the Souss-Massa plain in the Souss catchment and the Tadla region in the Oum'Er Bia catchment. The northern part of Morocco is affected by complex influences from the Atlantic Ocean to the west, the Mediterranean Sea to the north and the Sahara desert to the south (Bolle 2002; Knippertz et al. 2003). This results in high inter- and intra-annual variability in the distribution and amount of snow cover. On average, the snow season occurs over 4 to 6 mo between November and April in higher elevation areas (Boudhar et al. 2007, 2009). The study area was limited to areas $>1000 \mathrm{~m}$ above sea level (a.s.l.), mainly to limit the processing time of the MODIS

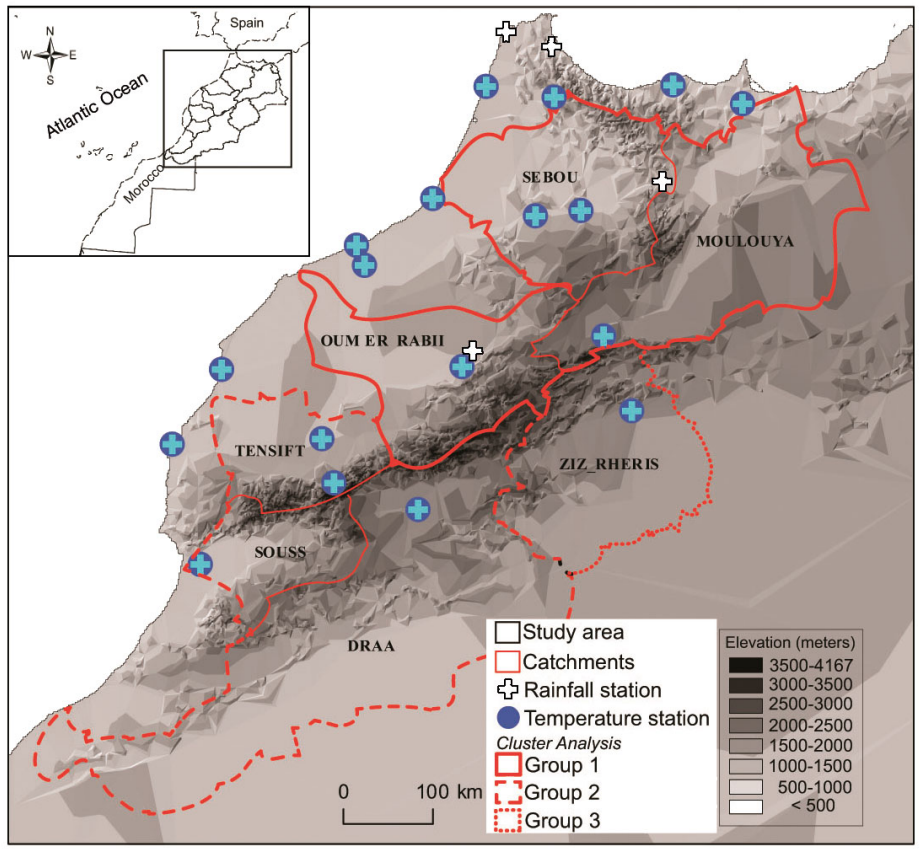

Fig. 1. Study region, encompassing areas $>1000 \mathrm{~m}$ a.s.l belonging to the 7 catchments that receive both rain and snow in Morocco. Locations of meteorological stations where temperature and/or rainfall are measured are shown. Three catchment groups with similar snow season dynamics are indicated (see Section 2.2) 
data set. This does not affect the monitoring of snowcovered areas, since lowlands are always snow-free in Morocco due to relatively high temperatures.

\subsection{MODIS snow cover products and preprocessing}

The MODIS instrument operates on both the Terra and Aqua spacecraft. Only the MODIS Terra fractional snow cover (FSC) L3 global gridded products (MOD10A1) version 5 at $500 \mathrm{~m}$ resolution, available from the National Snow and Ice Data Center (NSIDC), are used in this study (Hall et al. 2001). This data set has already been evaluated over the study region by Marchane et al. (2015), hereafter referred to as MA2015. The data have been organized by hydrological year (i.e. September to August), and cover 2000/2001 to 2012/2013. Due to cloud obscuration and potential cloud/snow confusion, MA2015 applied a simple 3-step spatial-temporal filter to the 4768 images available for the study period as follows:

(1) images with a cloud cover higher than $60 \%$ at the scale of the MODIS tiles are simply discarded; (2) if a pixel is detected as a cloud or if no decision was made by the MODIS snow mapping algorithm, a spatial filter replacing pixel value identified as cloud by a $100 \%$ snow cover if the pixel elevation is higher than the average of all neighbouring pixel identified as snow is applied; the average elevation of snowy pixels is computed individually for each catchment, in order to take into account specific conditions of snow occurrence; (3) finally, for remaining cloudy or 'no decision' pixels, a temporal filter is applied. If there is snow between $3 \mathrm{~d}$ before and $2 \mathrm{~d}$ after the date of acquisition, the pixel value is simply replaced by its closest neighbor value. Priority is given to preceding tiles because in case of a snow event during the two following days, correction could shift backward the event's timing. The temporal filter is by far more efficient than the spatial filter regarding the low cloud cover in the region (MA2015).

The 3-step filter results in a drastic decrease in the number of pixels identified as cloud or 'no decision' from $22.9 \%$ on average for the 7 catchments and for the whole study period to $0.8 \%$ remaining while maintaining $>6$ images $\mathrm{wk}^{-1}$. The ability of the cloudadjusted FSC to detect snow was then evaluated by comparison (1) to automatic snow depth measurements of 5 stations located in the Tensift and in the Draa catchments, and (2) to 15 FORMOSAT-2 images at $8 \mathrm{~m}$ resolution. In both cases, an accuracy of $89 \%$ was found (MA2015).
SCA time series for each catchment exhibit a high inter- and intra-annual variability, with snow-free periods in summer, and even complete ablation periods that occur during winter (cf. MA2015). In a search for coherent regions of snow cover variability, detrended SCA time series at the catchment level were grouped using cluster analysis. Hierarchical clustering with weighted pair-wise means based on correlative distance (i.e. $\sqrt{\frac{1-r}{2}}$ with $\mathrm{r}$ being the correlation factor between 2 time series) was used (Kaufmann \& Rousseeuw 2005). The correlative distance was preferred to more classical absolute distance criteria here, as we aimed to identify time series showing similar inter-annual variability patterns. The number of groups was fixed to 3 , based on a simple cross-correlation of the time series of the catchment's SCA. The classification revealed the 3 main groups of consistent inter-annual and seasonal snowpack dynamics, displayed in Fig. 1. Group 1 (Moulouya, Oum'Erbia and Sebou) consists of the northern catchments, whereas the Group 2 (Tensift, Souss, Draa) is located in the southern part of the study region. Finally, Group 3 consists solely of one catchment, Ziz Rheris, located at the south-western part of the Atlas chain. The time series of SCA at group level were extracted and summarized by seasonal indicators related to SCA: maximum SCA (SCAmax) and mean SCA by 2 mo periods (ON, DJ, FM and AM); and also related to timing of the snow season: onset and ablation dates and season duration. Data were aggregated by 2 mo periods to clearly analyze the complex temporal response of snow cover to NAO that a more typical 3 mo aggregation does not allow, because of the shortness of the snow season in Morocco. Those indicators were also computed for 2 distinct elevation classes (below and above $2500 \mathrm{~m}$ a.s.l.).

\subsection{Meteorological and North Atlantic Oscillation data sets}

The meteorological station data were provided by the Computational and Information Systems Laboratory (CISL) of the National Center for Atmospheric Research (NCAR) and were downloaded from the CISL Research Data Archive web site (http://rda. ucar.edu/). The station data is a part of a global surface database, which has been gathered by the National Climatic Data Center (NCDC). Further details can be found in Lott et al. (2001). Data at 37 ground stations measuring temperature and rainfall over Morocco were extracted from the database. The 
time steps of acquisition (hourly, 3-hourly, 6-hourly or daily) as well as the period of data availability are manifold, depending on the station. From a preliminary check, the period from 1993 to 2012 was selected for analysis, as it provides the most continuous time series. In addition, several studies highlighted non-stationary correlation between NAO and rainfall/temperature related to the displacement over time of the NAO pressure centers (cf. Hertig et al. 2015 for a review). For instance, Vicente-Serrano \& López-Moreno (2008) - based on linear correlation analysis between observed monthly rainfall data located over Europe and a monthly NAO index from 1902 to 2000 - found that the sign of the correlation was preserved but that the spatial pattern and the magnitude of correlation vary over time. Consequently, the other factors governing the choice of a recent enough period is to be able to assume stationarity in the the NAO-climate and NAO-snowseason-characteristics relationships, on one hand, and NAO and snow season characteristics that are available over a shorter period (2000-2013) on the other hand. In a second step, sub-daily acquisitions were aggregated to daily values using a simple average (sum) for temperature (rainfall) if all sub-daily data were available. Monthly values of average temperature and rainfall amounts were then computed if $\geq 80 \%$ of daily data were available for the considered month. The average temperature was preferred to minimum and maximum temperature because of the the change of time steps (from 3-hourly to daily values) of the raw time series over time. Only stations with $>80 \%$ of data from 1993 to 2013 were kept. Finally, 18 stations were taken for temperature and 22 for rainfall, whose locations are mapped in Fig. 1. Most stations are located north of the Atlas Mountains in the so-called Atlantic region defined by Knippertz et al. (2003) and Jarlan et al. (2014a); these stations are under the direct influence of atmospheric large-scale flow originating from the Atlantic and are not affected by the Atlas chain. Most of the stations are located at low elevation, with only 4 stations above $1000 \mathrm{~m}$ (the sky resort station of Oukamaiden and the 3 stations located south-west of the Atlas range listed above). In addition, NCEP re-analysis (Kalnay et al. 1996) of surface air temperature and rainfall rate available on a $2.5^{\circ}$ horizontal scale resolution for the period 1948 to present were also used for additional analysis.

The atmospheric circulation system of the northern hemisphere extratropics has been studied and summarized through several atmospheric indices belonging to the 'Northern Hemisphere Teleconnection
Patterns' (NHTP; Barnston \& Livezey 1987). Their impact on local climate (temperature and rainfall) has also been investigated (Hurrell \& Van Loon 1997). The NHTP indices are provided by the Climate Prediction Center (CPC) and calculated from rotated empirical orthogonal function (REOF, Varimax criterion) analysis of the $500 \mathrm{hPa}$ geopotentials. Only the leading mode is considered in this study: The NAO is characterized by a dipole of sea-level pressure with a trough above Iceland and an anticyclone above the Azores (Hurrell 1995). NAO has thus been defined by Hurrell (1995) as the difference in normalized sea level pressure (SLP) anomalies between stations of Lisbon (Portugal) and Stykkisholmur (Iceland). Nevertheless, as the SLP pattern associated with NAO shows an eastward movement since the late 1970s, the leading REOF of monthly mean 500 hPa geopotential anomalies from Barnston \& Livezey (1987) has been found to better capture the NAO pattern and variability (Lu \& Greatbatch 2002). Note that all the time series were linearly detrended before correlation analysis to avoid autocorrelation.

\section{RESULTS}

\subsection{Relationships between the NAO and rainfall}

Regarding NAO-rainfall relationships, Lamb \& Peppler (1987) were the first to show a strong inverse correlation between winter rainfall over Morocco (December-April) and winter NAO (December-February). Fig. 2 displays the simultaneous correlation between monthly rainfall anomalies and the NAO from December to May with colored points corresponding roughly to significance at the $95 \%$ level with a Student's $t$-test. Indeed, the 0.50 threshold only approximates the significance level, as threshold values range from 0.48 to 0.51 , depending on whether data is missing in the time series. The strength of correlation exhibits a strong variability in time and in space, but winter rainfall in Morocco appears to be inversely related to the NAO on average, meaning that above-normal rainfall may be expected with a negative NAO. A negative NAO is associated with low Azores and high Icelandic surface pressure. Indeed, excluding the south-western stations (Midelt, Er-Rachidia and Ouarzazate) along with the Mediterranean ones (Al Hoceima and Nouasseur), 15 of 17 stations located in the Atlantic region exhibit significant negative correlations in December and/or February, with a maximum correlation of -0.87 for Essaouira in February. The 2 re- 

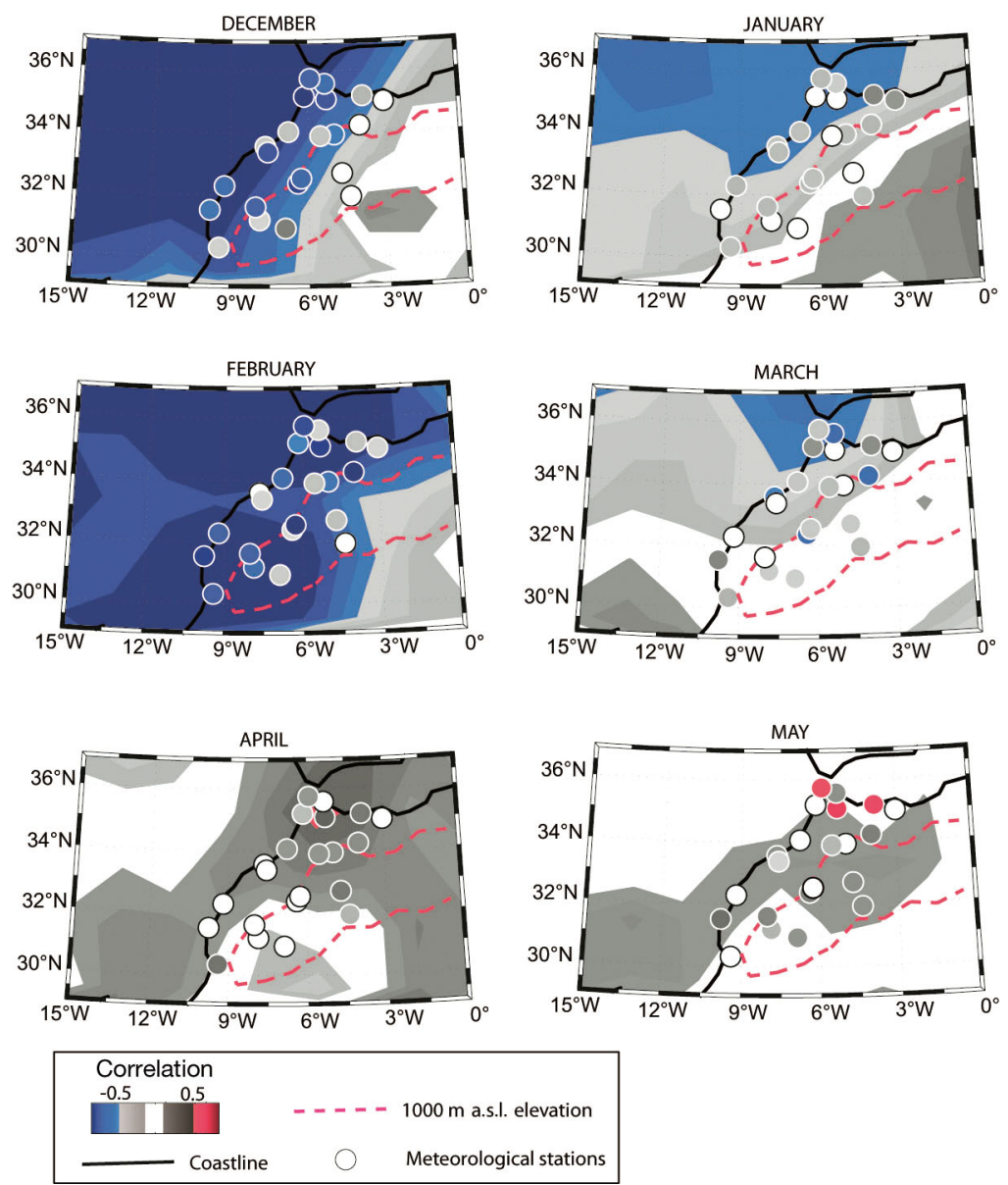

Fig. 2. Correlation between monthly NAO and rainfall from 1993 to 2012 for December, January, February, March, April, May. Spatial field: correlation with NCEP re-analysis; colored circles: station data (same color scale is used for both). Color displays correlation significant at the $95 \%$ level; gray scale is otherwise used

maining stations, although not significant, also show negative correlations, demonstrating that the sign of the correlation is consistent across stations: for the Fes station for instance, correlations are significant at the $90 \%$ level only with -0.48 and -0.49 during December and February, respectively. Another striking feature is the absence of significant correlations during January. This could be attributed to the slight bimodal distribution of rainfall in Morocco with a first peak in late November and another one of lesser extent, in April; January corresponding to a minimum of rainfall (Jlidene \& Balaghi 2009). The rainfall anomalies during this month seem to be significantly less related to NAO than December and February. Previous studies (Lamb \& Peppler 1987, Knippertz et al. 2003) may have masked this particular behavior by focusing on the seasonal rainfall amount during
DJF. The correlation significantly declines after February, as expected. Lagged correlations, although with lower values, present similar structure for the NAO with a 1 mo lag, but correlations strongly decline as soon as the lag reaches 2 mo (not shown). This is also in agreement with previous studies (see Marshall et al. 2001 and references therein).

NCEP rainfall rates at the surface level were also correlated with monthly NAO (Fig. 2). A similar negative correlation pattern covering the north-western part of the study area is highlighted for February and, to a lesser extent, December. This pattern appears even more homogeneous than the one obtained with ground station data, due to the $2.5^{\circ}$ horizontal resolution of NCEP re-analysis. The absence of correlation with the January rainfall rate is also particularly prominent. The results therefore reveal that the inverse relationship between rainfall and NAO over Morocco is consistent whether ground station data or re-analysis is used.

\subsection{Relationships between NAO and temperature}

The same approach as above based on simple correlation and lagged correlation was adopted. The highest correlations are obtained when the NAO index leads temperature by 1 mo. Fig. 3 displays the 1 mo lagged correlation between NAO and monthly temperature from the 18 stations passing our quality check criterion and the correlation map between NAO and NCEP re-analysis of air temperature at the surface level. As with rainfall, a negative correlation is highlighted, meaning that a negative (positive) phase of the NAO is associated with above-normal (below-normal) temperature. This could be attributed to the enhanced advection from the warm ocean during the negative phase. This is prominent for both data sets, except that lagged correlation with station data are more scattered than with the NCEP re-analysis. Two significant differences can be highlighted with regards to the NAO-rainfall correlation maps:

(1) Lagged correlation is significant far inland even on the southern side of the Atlas range: stations of Er-Rachidia and Midelt in February exhibit a negative correlation of -0.67 and -0.56 , respectively. In April, the 3 stations located south of the Atlas range, 

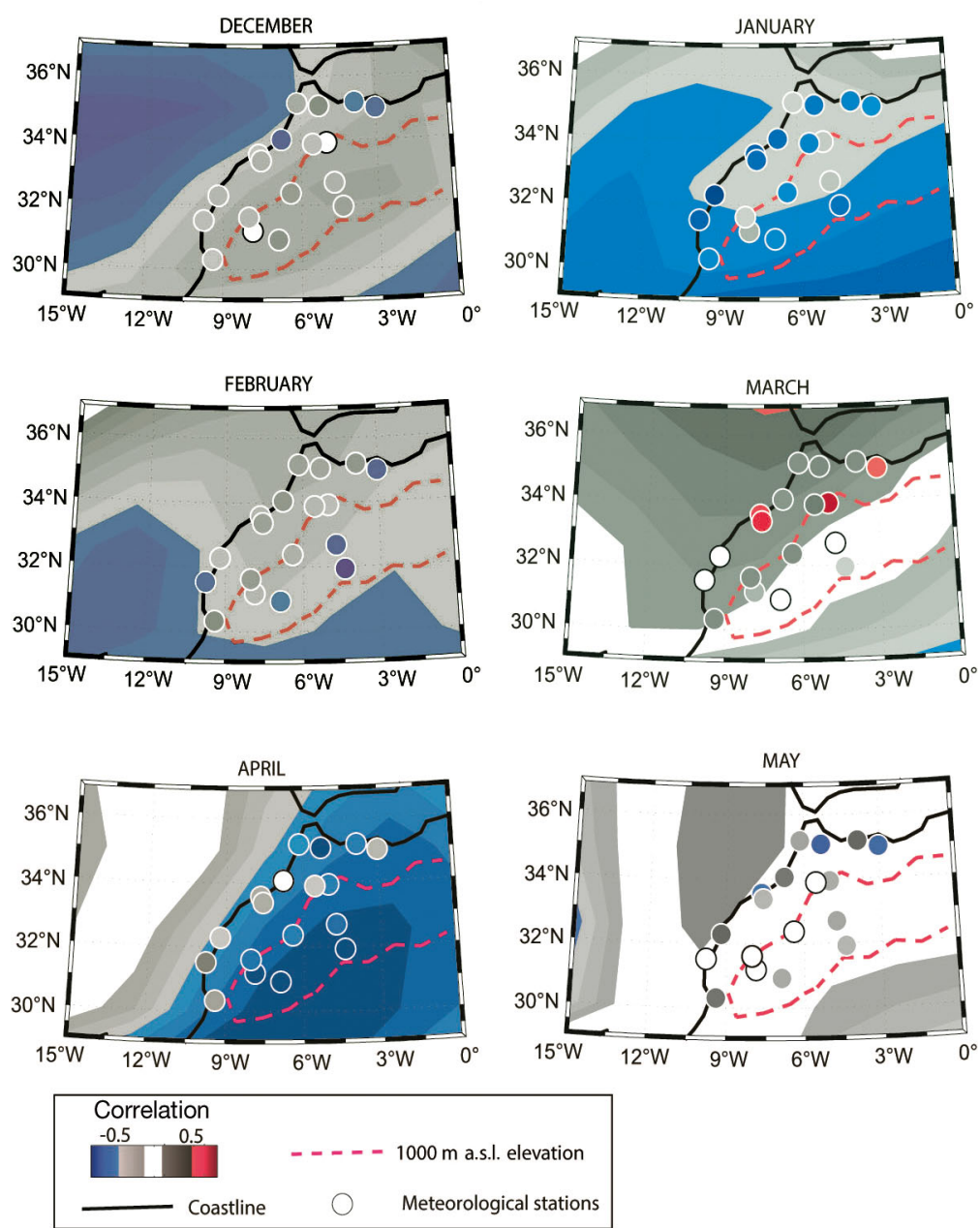

Fig. 3. Same as Fig. 2 but for monthly temperature (lagged by $1 \mathrm{mo}$ ) and NAO

including Ouarzazate, show significant correlation with NAO.

(2) The lagged correlation remains significantly late in the season. In April, all the southern stations exhibit very high negative values and a clear spatial pattern of negative correlation over the same area is also prominent for NCEP-re-analysis.

Finally, a dipole pattern of correlation appears in March on the NCEP re-analysis data with a positive correlation in the northwest of the area and, to a lesser extent, a negative correlation in the southeast. Although not significant at the $95 \%$ level, the northwestern pattern does not seem to be an artifact, as it is supported by the positive correlation shown by most of the station observations located on the northern side of the Atlas chain. Correlation is significant for 4 stations. Despite this apparent consistency, no potential explanation could be found at the present time.

\subsection{Impact of the NAO on SCA seasonal indicators}

In order to gain insight into the relationship between the NAO and SCA in Morocco, lagged correlations between monthly NAO and the different indicators summarizing the snow season were analyzed. No significant correlation was found with the onset date, either for the full range of elevation or by elevation classes. Fig. $4 \mathrm{a}$, b displays the lagged correlation analysis results by groups for duration and ablation date. The first striking result is a positive correlation significant at the $95 \%$ level for both timing indicators, meaning that a positive (negative) NAO favors longer (shorter) snow seasons through later (sooner) disappearance of snow cover. This is consistent with the correlation of March NAO with air temperature in April late in the snow season. Stated differently, milder temperatures coming with negative phases of the NAO favor an early disappearance of snow. In addition, this underlines the dominant influence of temperature anomalies on snowpack, induced by the NAO rather than an NAO-rainfall effect, which has been shown to be weak beyond the winter months; an NAO-rainfall effect would also imply a negative correlation. Finally, no clear spatial patterns can be highlighted from Fig. 4a,b, as a positive correlation is present for the 3 groups (though not significant for the snow duration within the Group 2). For the latter, the shape of the curve is close to the 2 others with a significant increase for February and March. This is in line with the homogeneous positive correlation pattern found between the NAO and temperature (Fig. 3).

Regarding quantitative indicators, no correlation is found either with SCAmax or with SCAmean at the seasonal scale. By contrast, SCAmean in April-Mayand to a lesser extent in December-January (for areas $>2500 \mathrm{~m}$ a.s.l.) - are positively correlated with NAO as shown by Fig. 4c,d. The correlation results for both indicators also supports the dominance of temperature effects: (1) the sign of correlation is positive; if rainfall effect was dominant, a negative sign would have been expected; (2) a significant correlation is found for the 3 groups including the third group located south of the Atlas mountains, in line with the spatial pattern of the correlation between NAO and temperature that covers the entire country in April (Fig. 3), while rainfall-NAO is prominent 

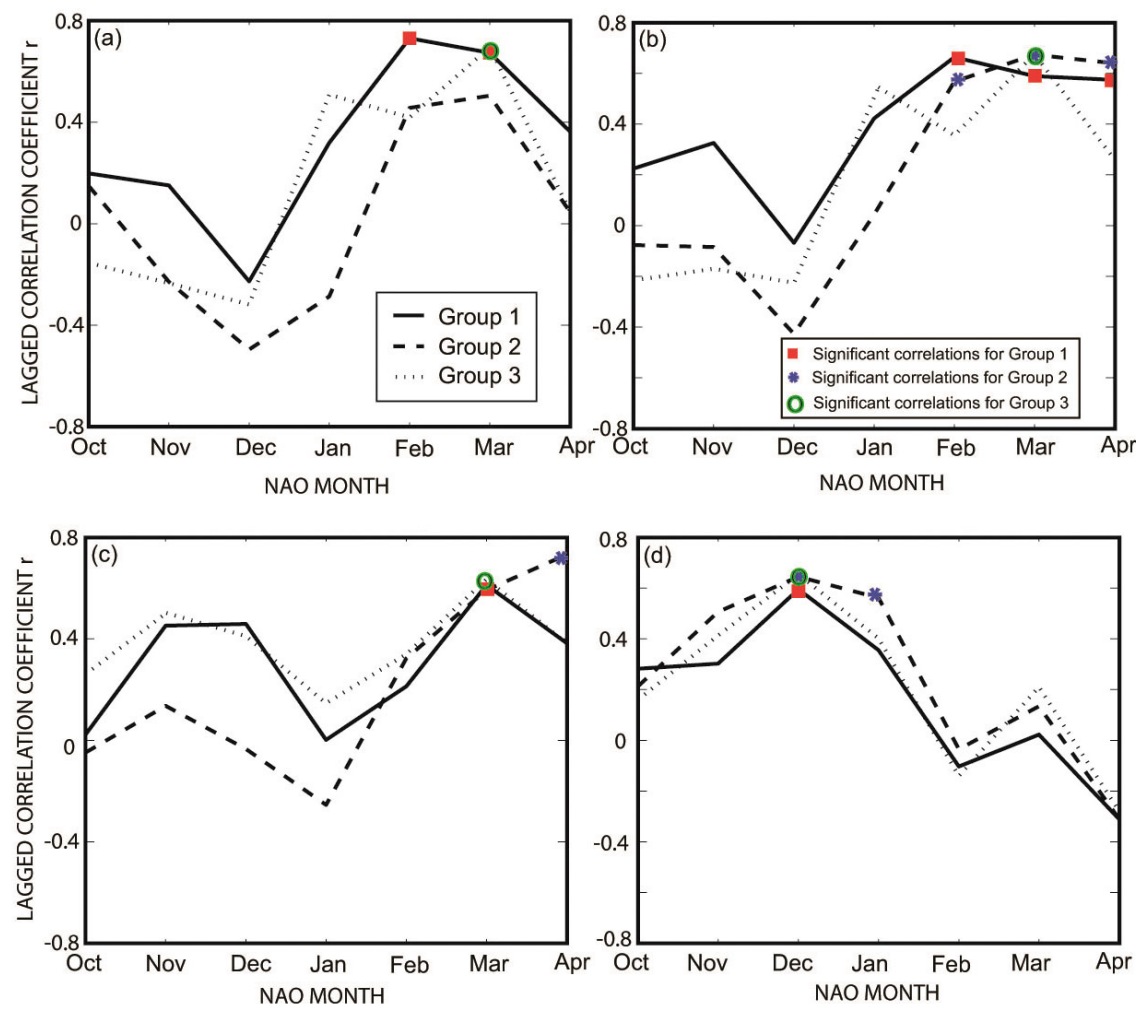

Fig. 4. Lagged correlation between monthly NAO and indicators of the snow season (2001-2013): (a) duration; (b) ablation date; (c) mean SCA for April and May; (d) mean SCA for December and January for areas $>2500 \mathrm{~m}$ a.s.l. The symbols correspond to significant correlation values at the $95 \%$ level

along the Atlantic coast only (Fig. 2); and (3) the timing of the correlation that occurs mainly late in the season when the correlation between rainfall and NAO has disappeared (Fig. 2) in contrast with the correlation between the NAO and temperature. The positive correlation between SCA in April-May and monthly NAO is certainly the result of the correlation between SCAmean and the ablation date, as correlation values are $0.79,0.71$ and 0.74 for Groups 1,2 and 3 , respectively. Stated differently, earlier (later) melt will bring lower (higher) average SCA. By contrast, the positive correlation found for SCAmean of higher elevation areas in December-January could be related to an enhanced (reduced) snow accumulation due to below-normal (above-normal) temperature associated with positive (negative) NAO phases.

\section{DISCUSSION AND CONCLUSIONS}

In this study, the relationship between NAO and different snow cover characteristics derived from remote-sensing products related to timing and quantity of seasonal snow have been analyzed for first time. NAO was initially shown to be negatively correlated to rainfall for the northern part of the country and the northern edge of the Atlas range in winter (December and February), in line with previous studies. Concerning temperature, in contrast with rainfall, the negative correlation pattern persists far inland, even south of the Atlas, and lasts until spring (March and April). These results highlight a possible competing influence of NAO on snowpack dynamics through rainfall and temperature. Indeed, enhanced rainfall that comes with negative phases could favor snow accumulation in the mountains, whilst the simultaneous milder temperature could favor enhanced melting. Conversely, below-normal rainfall associated with NAO positive phases is expected to limit snow accumulation, whereas below-normal temperature should slow down melting. In order to strengthen the analysis, the correlation maps were re-computed (Figs. A1-A3 in the Appendix) using 2 extensively used data sets, namely CRU version TS3.23, composed of gridded averaged air temperature and rainfall data at $0.5^{\circ}$ resolution (Harris et al. 2014) and GPCC rainfall version 7 at $0.5^{\circ}$ resolution (Schneider et al. 2015). A time period of $30 \mathrm{yr}$ covering 1983-2012 was used to be compliant with the World Meteorological Organization standard. Although correlation patterns differ slightly in location and strength, these new correlation maps are in line with the results summarized above. The NAO impact on SCA is shown to be the result of the NAO's influence on temperature, as the correlation with both timing and quantity indicators is always positive and appears late in the snow season: this means that positive (negative) NAO in spring (March and April) may favor later (earlier) melting and associated higher (lower) SCA on average. It is possible that, with regard to snowpack dynamics, the competing effects of NAO on temperature and rainfall cancel each other out during the core of the season, thus masking the influence of the NAO on snowpack. Nevertheless, the complex topography of the Atlas chain can also help mask the influence of the NAO on precipitation (including 
snowfall) by pertubing the large-scale flow originating in the Atlantic. The absence of relationships between SCA and the NAO at the beginning of the season is more expected, as various authors have shown the tropical control on rainfall through the perturbation of Hadley cells by SST anomalies in the tropical Atlantic (Knippertz \& Martin 2007). In addition, significant linkages between SST in the tropical Atlantic and both cereal grain yields and photosynthetic activity of vegetation have been found (Jarlan et al. 2014a,b), but no linkages with mid-latitude atmospheric variability at this period of the year.

The high interannual variability of Mediterranean climate has led to the construction of a large number of dams throughout the region to provide reliable water sources throughout the year. The results of this study are of prime importance for dam water management in highlighting the influence of the NAO on snow cover melt in spring, which is a major contribution to runoff. Some studies suggest that a global tropospheric warming is likely to favor an increase in the occurrence of the NAO positive phase in future (Rind et al. 2005, Rodriguez-Puebla \& Nieto 2010). The results of this study-even if its reliability needs to be confirmed with longer time series of SCAdemonstrate that such periods of enhanced positive phase could favor a longer snow season by delaying the date of complete ablation. Finally, the linear statistics approaches used in this study could also mask non-linear linkages between the NAO and snowpack dynamics. For a future study, we are currently evaluating the potential of mutual information functions in assessing possible non-linear relationships between the NAO and snowpack dynamics.

Acknowledgements. This work was carried out under the auspices of the Joint International Laboratory TREMA (http://trema.ucam.ac.ma). In addition to the CNRST scholarship awarded to A. M., financial support for this study was provided by IRD, Moroccan project (Recherche Sectorielle, RS/09/2011, CNRST), ANR AMETHYST (ANR-12-TMED0006-01) and the MISTRALS/ENVIMED program.

\section{LITERATURE CITED}

Abrams M, Bailey B, Tsu H, Hato M (2010) The ASTER Global DEM. Photogramm Eng Remote Sensing 76:344-348

Barnston AG, Livezey RE (1987) Classification, seasonality and persistance of low-frequency atmospheric circulation patterns. Mon Weather Rev 115:1083-1126

Bolle HJ (2002) Mediterranean climate: variability and trends. Springer-Verlag, Berlin

Boudhar A, Duchemin B, Hanich L, Chaponnière A and others (2007) Snow covers dynamics analysis in the Moroccan High Atlas using SPOT-VEGETATION data.
Sécheresse 18:1-11

Boudhar A, Hanich L, Boulet G, Duchemin B, Berjamy B, Chehbouni A (2009) Evaluation of the snowmelt runoff model in the Moroccan High Atlas Mountains using two snow-cover estimates. Hydrol Sci J 54:1094-1113

Boudhar A, Duchemin B, Hanich L, Jarlan L and others (2010) Long-term analysis of snow-covered area in the Moroccan High-Atlas through remote sensing. Int J Appl Earth Obs Geoinf 12:S109-S115

Cook BI, Smith TM, Mann ME (2005) The North Atlantic Oscillation and regional phenology prediction over Europe. Glob Change Biol 11:919-926

Crane RG, Anderson MR (1984) Satellite discrimination of snow/cloud surfaces. Int J Remote Sens 5:213-223

Frei A, Tedesco M, Lee S, Foster J, Hall DK, Kelly R, Robinson DA (2012) A review of global satellite-derived snow products. Adv Space Res 50:1007-1029

Hall D K, Riggs GA, Salomonson VV (2001) Algorithm theoretical basis document (ATBD) for the MODIS Snow and sea ice-mapping algorithms.

Hamly ME, Sebbari R, Lamb PJ, Ward N, Portis DH (1998) Towards the seasonal prediction of Moroccan precipitation and its implications for water resources management. In: Proc 'Water resources variability in Africa during the XXth century' Conf, Abidjan, Ivory Coast, November 1998, IAHS, p 79-87

Harris I, Jones PD, Osborn TJ, Lister DH (2014) Updated high-resolution grids of monthly climatic observationsthe CRU TS3.10 dataset. Int J Climatol 34:623-642

> Hertig E, Beck C, Hertig E, Wanner H, Jacobeit J (2015) A review of non-stationarities in climate variability of the last century with focus on the North Atlantic-European sector. Earth Sci Rev 147:1-17

Hurrell JW (1995) Decadal trends in the North Atlantic Oscillation and relationships to regional temperature and precipitation. Science 269:676-679

Hurrell JW (1996) Influence of variations in extratropical wintertime teleconnections on Northern Hemisphere temperature. Geophys Res Lett 23:665-668

Hurrell JW, Van Loon H (1997) Decadal variations in climate associated with the North Atlantic Oscillation. Clim Change 36:301-326

Jarlan L, Driouech F, Tourre Y, Duchemin B and others (2014a) Spatio-temporal variability of vegetation cover over Morocco (1982-2008): linkages with large scale climate and predictability. Int J Climatol 34:1245-1261

Jarlan L, Abaoui J, Duchemin B, Ouldbba A and others (2014b) Linkages between common wheat yields and climate in Morocco (1982-2008). Int J Biometeorol 58: 1489-1502

Jlidene M, Balaghi R (2009) Le risque de sècheresse en agriculture pluvial. Cas des céréales, Bulletin mensuel d'information et de liaison du PNTTA, Transfert de technologie en Agriculture, 181

Kalnay E, Kanamitsu M, Kistler R, Collins W and others (1996) The NCEP/NCAR 40-year reanalysis project. Bull Am Meteorol Soc 77:437-471

Kaufman L, Rousseeuw PJ (2005) Finding groups in data: an introduction to cluster analysis. Wiley, Hoboken, NJ

> Kim Y, Kim K, Kim B (2013) Physical mechanisms of European winter snow cover variability and its relationship to the NAO. Clim Dyn 40:1657-1669

Knippertz P, Martin JE (2007) The role of dynamic and diabatic processes in the generation of cut-off lows over Northwest Africa. Meteorol Atmos Phys 96:3-19 
Knippertz P, Christoph M, Speth P (2003) Long-term precipitation variability in Morocco and the link to the large-scale circulation in recent and future climates. Meteorol Atmos Phys 83:67-88

Lamb PJ, Peppler RA (1987) North Atlantic Oscillation: concept and an application. Bull Am Meteorol Soc 68: 1218-1225

López-Moreno JI, Vicente-Serrano SM, Morán-Tejeda E, Lorenzo-Lacruz J, Kenawy A, Beniston M (2011) Effects of the North Atlantic Oscillation (NAO) on combined temperature and precipitation winter modes in the mediterranean mountains: observed relationships and projections for the 21st century. Global Planet Change 77:62-76

Lott N, Baldwin R, Jones P (2001) The FCC integrated surface hourly database: a new resource of global climate data. Technical Report 2001-01, National Climate Data Center, Asheville, NC

Lu J, Greatbatch RJ (2002) The changing relationship between the NAO and Northern Hemisphere climate variability. Geophys Res Lett 29(7):1148, doi:10.1029/2001GL 014052

Marchane A, Jarlan L, Hanich L, Boudhar A and others (2015) Assessment of daily MODIS snow cover products to monitor snow cover dynamics over the Moroccan Atlas mountain range. Remote Sens Environ 160:72-86

Mariotti A, Dell'Aquila A (2012) Decadal climate variability in the Mediterranean region: roles of large-scale forcings and regional processes. Clim Dyn 38:1129-1145
Marshall J, Kushnir Y, Battisti D, Chang P and others (2001) North Atlantic climate variability: phenomena, impacts and mechanisms. Int J Climatol 21:1863-1898

- Painter TH, Dozier J (2004) Measurements of the hemispherical-directional reflectance of snow at fine spectral and angular resolution. J Geophys Res 109:D18115, doi: 10.1029/2003JD004458

Schneider U, Becker A, Finger $\mathrm{P}$, Meyer-Christoffer $\mathrm{A}$, Rudolf B, Ziese M (2015) GPCC full data reanalysis version 7.0 at $0.5^{\circ}$ : monthly land-surface precipitation from rain-gauges built on GTS-based and historic data. doi: 10.5676/DWD_GPCC/FD_M_V7_050

Schulz O, De Jong C (2004) Snowmelt and sublimation: field experiments and modelling in the High Atlas Mountains of Morocco snowmelt and sublimation. Hydrol Earth Syst Sci 8:1076-1089

Vicente-Serrano SM, López-Moreno JI (2008) Differences in the non-stationary influence of the North Atlantic Oscillation on European precipitation under different scenarios of greenhouse gas concentrations. J Geophys Res Lett 35:L18710, doi:10.1029/2008GL034832

> Viviroli D, Dürr HH, Messerli B, Meybeck M, Weingartner R (2007) Mountains of the world, water towers for humanity: typology, mapping, and global significance. Water Resour Res 43:W07447, doi:10.1029/2006WR005653

Wang D, Wang C, Yang X, Lu J (2005) Winter northern hemisphere surface air temperature variability associated with the Arctic Oscillation and North Atlantic Oscillation. Geophys Res Lett 32:4-7

\section{Appendix}
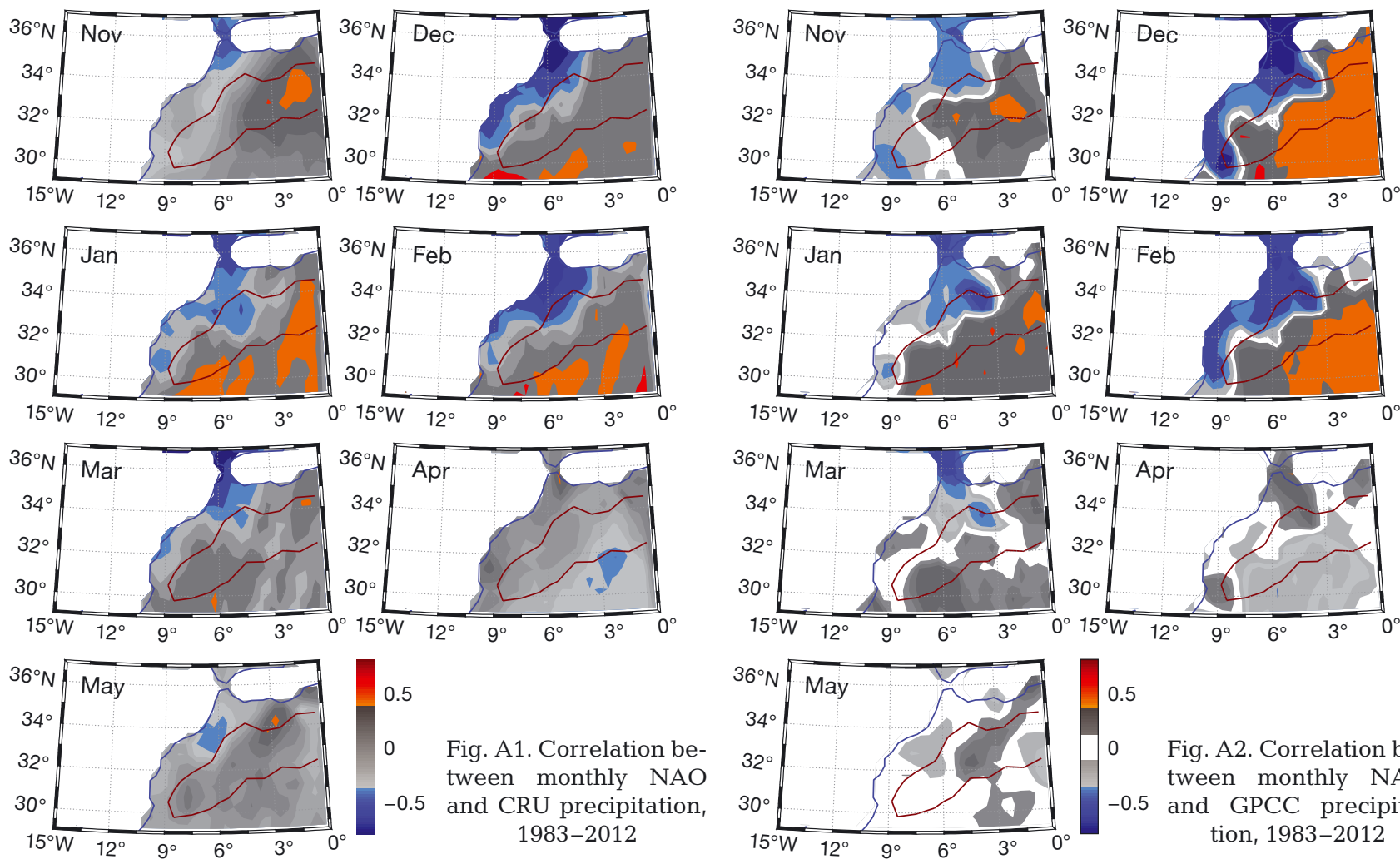

Fig. A1. Correlation between monthly NAO and CRU precipitation, 1983-2012

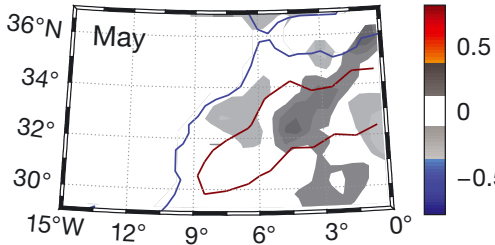

Fig. A2. Correlation between monthly NAO 5 and GPCC precipitation, 1983-2012 

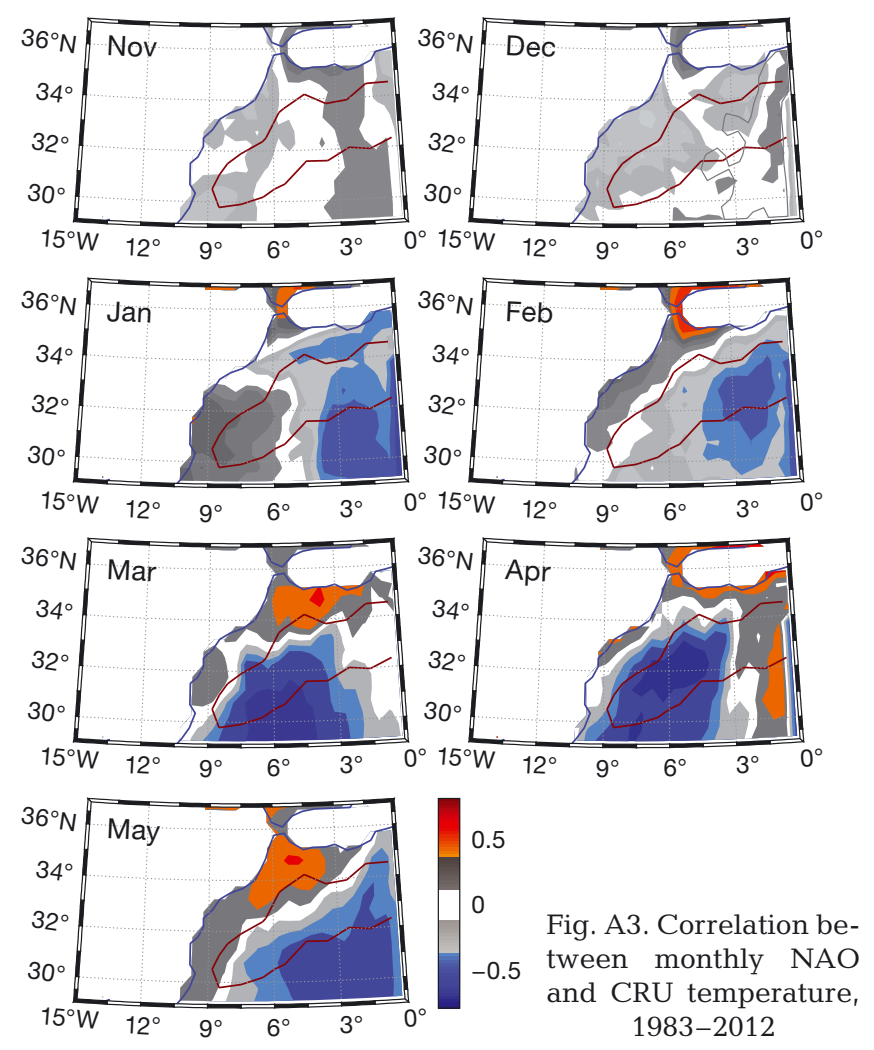

Editorial responsibility: Eduardo Zorita, Geesthacht, Germany
Submitted: October 26, 2015; Accepted: June 6, 2016

Proofs received from author(s): July 21, 2016 